www.jmscr.igmpublication.org Impact Factor 5.244

Index Copernicus Value: 83.27 ISSN (e)-2347-176x ISSN (p) 2455-0450 crossref DOI: _https://dx.doi.org/10.18535/jmscr/v4i11.20

\title{
A Comparative Study of Inj. Labetalol \& Oral Nifedipine in Severe Hypertension in Pregnancy
}

\author{
Authors \\ Dr Rinkesh Meena ${ }^{1}$, Dr Dharmraj Meena ${ }^{2}$ \\ ${ }^{1}$ Medical Officer, Govt. Hospital, Baran (Raj) \\ ${ }^{2}$ Assistant Professor, Department of Surgery Govt. Medical College, Kota (Raj.) \\ Corresponding Author \\ Dr Dharmraj Meena \\ Email:dr.dharm2000@gmail.com
}

\begin{abstract}
PIH is a form of high blood pressure in pregnancy. PIH is also called toxemia or preeclampsia. It occurs most often in young women with a first pregnancy. The proposed study was clinical trial of comparison of oral administration of tab. Nifedipine and inj labetalol in case of severe PIH.

Criteria for inclusion in the study were women with blood pressure more than 160/110mm hg.

In nifedipine group $76 \%$ patients had a DBP in the range of $110-120 \mathrm{mmHg}$, of these $32 \%$ responded favourably but in remaining cases other drugs was added.

Similarly in Labetalol group $72 \%$ had DBP in the range of 110-120 $\mathrm{mmHg}$, of which $60 \%$ responded to labetalol.

It appears that inj Labetalol is more effective in lowering the diastolic BP in severe PIH as compared to Nifedipine. Further fewer patients needed other anti hypertensive drug in Labetalol group.

Labetalol group had favorable parameters in all aspects. However larger studies are required to establish the superiority of inj Labetalol in PIH.

KEYWORDS:- DBP (Diastolic Blood Pressure), SBP (Systolic Blood Pressure)
\end{abstract}

\section{INTRODUCTION}

According to National High Blood Pressure Education Programme Working Group (NHBPEP) and American College of Obstetricians and Gynaecologists (ACOG) hypertension in pregnancy is defined as a diastolic Blood Pressure (BP) of $90 \mathrm{~mm} \mathrm{Hg}$ or higher and systolic Blood Pressure level of $140 \mathrm{~mm} \mathrm{Hg}$ or higher after 20 weeks of gestation in a woman with previous normal blood pressure.

$\mathrm{PIH}$ or toxemia or preeclampsia is a form of high blood pressure in pregnancy. It occurs in about
$5 \%$ to $8 \%$ of all pregnancy. It occurs most often in young women with a first pregnancy. It is more common in twin pregnancy, in women with chronic hypertension, preexisting diabetes and in women who had PIH in a previous pregnancy.

As per NHBPEP on high Blood pressure in pregnancy-

1. Normal or acceptable BP in pregnancy if $\mathrm{SBP}<140 \mathrm{~mm} \mathrm{Hg}$ and $\mathrm{DBP}<90 \mathrm{~mm} \mathrm{Hg}$.

2. Mild hypertension if SBP 140 to $150 \mathrm{~mm}$ $\mathrm{Hg}$ or DBP 90 to $109 \mathrm{~mm} \mathrm{Hg}$.

3. Severe hypertension in pregnancy if SBP $>160 \mathrm{~mm} \mathrm{Hg}$ or DBP $>110 \mathrm{~mm} \mathrm{Hg}$. 
Diagnostic criteria of severe PIH

- $\mathrm{SBP}>160 \mathrm{~mm} \mathrm{Hg}$.

- $\mathrm{DBP}>110 \mathrm{~mm} \mathrm{Hg}$

Proteinuria $>5 \mathrm{gm}$ in 24 hour urine collection.

Oliguria $<400 \mathrm{ml}$ urine in 24 hours.

Headache, visual disturbances, upper abdominal pain, convulsions, elevated serum creatinine, thrombocytopenia, hyperbilirubinemia, liver enzyme elevation, fetal growth retardation, pulmonary oedema.

Severe PIH is a very serious disease and is the second leading cause of maternal mortality (NHBPEP working group US DHHS 2000) accounting for $16-18 \%$ of all maternal deaths (ACOG 2002 Cox kill patride on Gallu 2004).

If severe PIH is treated early and effectively, maternal mortality is low, if the disease is allowed to progress to the HELLP syndrome (haemolysis, elevted liver enzyme, low platelet count) Eclampisa, mortality increases to as high as $24 \%$ and morbidity level even higher.

Perinatal mortality related to mild $\mathrm{PIH}$ ranges from $1-8 \%$, increases to an overall average of $12 \%$ in severe PIH. Higher incidence is inversely related to the onset of eclampsia, higher being in early onset.

Perinatal mortality and morbidity occur either directly as a result of uteroplacental insufficiency, abruption placenta and still birth or indirectly due to prematurity.

Antihypertensive drugs used in sever PIH are as follows-

Labetalol

Calcium channel blocker (Nifedipine and nicardipine).

Hydralazine

Nitroglycerine or sodium nitropruside.

\section{Newer Drugs}
1. Isradipine
2. Nicardipine
3. Fenoldopam
4. Epoprostenol

\section{AIMS AND OBJECTIVES}

The aims and objectives of present study are to see the effect of inj. labetalol and tab nifedipine on the following parameters:

1. To see the effect of above mentioned drugs on blood pressure.

2. To compare fetal out come in patients who were receiving labetalol and nifedipine.

3. To compare the efficacy and safety of above mentioned drugs.

4. To compare the mode of delivery. Need for induction of labour and induction delivery interval between two groups.

Landheimer Barron in 19851 reported that hypertension complicates $5-10 \%$ of all pregnancies. Pritchard et al, 19852 stated that pregnancy induced hypertension also commonly known as toxaemia of pregnancy.

NHBPEP(2000) reported that severe hypertension in pregnancy should be promptly,albeit carefully,to prevent cerebral haemorrhage and hypertensive encephalopathy

Sibai BM,et al 200763 reported that incidence of severe $\mathrm{PIH}$ is $0.9 \%$ in united states.

\section{MATERIAL AND METHODS}

The proposed study was clinical trial of comparison of oral administration of tab. Nifedipine and inj labetalol in case of severe PIH. Criteria for inclusion in the study were women with blood pressure more than 160/110mm hg.

All these women were admitted to hospital and detailed history including Name, Age, Religion, Socio-economic status, obstetric and menstrual history and history of immunization for tetanus were recorded. General physical and systematic examination was done to rule out any other disease.

Abdominal examination was done to assess the size of uterus, amount of liquor, presentation of fetus.

Blood Pressure was measured at the time of admission with a mercury sphygmomanometer in semi recumbent position. Korot koff sound $1 \& 4$ was used as cut off line for systolic and diastolic blood pressure. 


\section{JMSCR Vol||04||Issue||11||Page 13638-13643||November}

The patients were then randomly allocated in two group, Group A treated with inj. labetalol $20 \mathrm{mg}$ IV bolus, Group B treated with tab nifedipine 10 $\mathrm{mg}$, each group comprising of 25 patients.

Blood pressure was recorded after $15 \mathrm{~min}$. Dose of anti hypertensive was doubled every $15 \mathrm{~min}$ to keep diastolic blood pressure below $110 \mathrm{~mm}$ of $\mathrm{Hg}$ with maximum dose of labetalol -300mg \& nifedipine $-90 \mathrm{mg}$.
All patients were kept in under observation from time of admission until $48 \mathrm{hr}$ after delivery to ensure accurate measurement of Blood pressure and progressive of disease. Mode of delivery whether spontaneous or induced, normal or caesarean was noted in both groups, fetal weight, maternal and neonatal complication were noted in each case.

\section{OBSERVATIONS}

Table 1: Control of Blood Pressure

Comparison between two group of drugs

\begin{tabular}{|c|c|c|c|}
\hline \multicolumn{4}{|l|}{ Nifedipine Group } \\
\hline BP at time of admission & $\begin{array}{l}\text { Diastolic } \\
\text { Blood Pressure }\end{array}$ & Reduction in BP in 15 Mint. & $\begin{array}{l}\text { Need to increase in dose or need to } \\
\text { add other antihypertensive }\end{array}$ \\
\hline \multicolumn{4}{|l|}{ No. of Patients } \\
\hline 19 & $110-120$ & 8 & 11 \\
\hline 5 & $120-130$ & 2 & 3 \\
\hline 0 & $130-140$ & - & 0 \\
\hline 1 & $140-150$ & & 1 \\
\hline Total & & $10(40 \%)$ & $15(60 \%)$ \\
\hline \multicolumn{4}{|l|}{ Labetalol } \\
\hline 18 & $110-120$ & 15 & 3 \\
\hline 4 & $120-130$ & 3 & 1 \\
\hline 2 & $130-140$ & - & 2 \\
\hline 1 & $140-150$ & - & 1 \\
\hline Total & & $18(72 \%)$ & $7(28 \%)$ \\
\hline
\end{tabular}

In nifedipine group 19 cases $(76 \%)$ patients had a DBP in the range of $110-120 \mathrm{mmHg}$, of these 8 cases $(32 \%)$ responded favourably but in remaining cases other drugs was added.

Similarly in Labetalol group 18 cases (72\%) had DBP in the range of 110-120 mmHg, of which 15 cases $(60 \%)$ responded to labetalol.

Table 2: Comparison of Need of augmentation and Induction of Labour during treatment between two groups of drug : Total Cases : 50 (25 Each)

\begin{tabular}{|l|c|c|c|c|}
\hline Drug & Nifedipine & & Labetalol & \\
\hline Labour & No. of cases & Percentage of Cases & No. of Cases & Percentage of Cases \\
\hline Augmentation & 9 & $36 \%$ & 10 & $40 \%$ \\
\hline Induced & 16 & $64 \%$ & 15 & $60 \%$ \\
\hline
\end{tabular}

Induction rate is slightly more in nifedipine group as a compared to labetalol group, as shown in above table.

Table 3: Comparison of mode of delivery between two groups of Drug Total Cases : 50 (25 Each)

\begin{tabular}{|l|c|c|c|c|}
\hline Drug & Nifedipine & & Labetalol & \\
\hline Group & No. of Cases & Percentage of Cases & No. of Cases & Percentage of Cases \\
\hline Normal & 14 & $56 \%$ & 16 & $64 \%$ \\
\hline Cesarean Section & 11 & $44 \%$ & 8 & $32 \%$ \\
\hline Hysterotomy & - & & 1 & $4 \%$ \\
\hline
\end{tabular}

Above table shows that 16 cases $(64 \%)$ in labetalol group had normal delivery while 8 cases (32\%) needed caesarean sections. While in nifedipine group 14 cases (56\%) delivered normally and 11 cases $(44 \%)$ had LSCS. 
Table 4: Comparison of Perinatal outcome between two groups of Drug

Total Cases : 50 (25 Each)

\begin{tabular}{|l|c|c|c|c|}
\hline Drug & Nifedipine & & Labetalol & \\
\hline Group & No. of Cases & Percentage of Cases & No. of Cases & Percentage of Cases \\
\hline Baby Mother shifted & 12 & $48 \%$ & 15 & $60 \%$ \\
\hline Nursery shifted & 9 & $36 \%$ & 6 & $24 \%$ \\
\hline Intra uterine death & 4 & $16 \%$ & 4 & $16 \%$ \\
\hline
\end{tabular}

Above table shows that $60 \%$ babies delivered in a labetalol group shifted to mother and only $24 \%$ shifted to nursery while in nifedipine group $48 \%$ babies shifted to mother and $36 \%$ babies shifted to nursery. $16 \%$ of intra uterine death was reported in both groups.

Table 5: Comparison of side effects between two groups of drug

Total Cases : 50 (25 Each)

\begin{tabular}{|l|c|c|c|c|}
\hline Drug & Nifedipine & Labetalol & \\
\hline Side Effects & No. of Cases & Percentage of Cases & No. of Cases & Percentage of Cases \\
\hline Headache & 4 & $16 \%$ & 2 & $8 \%$ \\
\hline Tachycardia & 7 & $28 \%$ & & \\
\hline Postural hypotension & 4 & $16 \%$ & 2 & $8 \%$ \\
\hline
\end{tabular}

Above table shows that side effects like headache, tachycardia and postural hypotension were more in nifedipine as compared with labetalol group.

Table 6: Blood pressure in both groups of drug after delivery

Total Cases: 50 (25 Each)

\begin{tabular}{|l|c|c|c|c|}
\hline Drug & Nifedipine & & labetalol & \\
\hline Blood Pressure & No. of Cases & Percentage of Cases & No. of Cases & Percentage of Cases \\
\hline Systolic & & & & \\
\hline Up to 130 & 2 & $8 \%$ & 4 & $16 \%$ \\
\hline $130-140$ & 5 & $20 \%$ & 6 & $24 \%$ \\
\hline $140-150$ & 10 & $40 \%$ & 5 & $20 \%$ \\
\hline $150-160$ & 5 & $20 \%$ & & \\
\hline$>160$ & & & & $12 \%$ \\
\hline Diastolic & 2 & $8 \%$ & 3 & $48 \%$ \\
\hline Up to 80 & 13 & $52 \%$ & 12 & $36 \%$ \\
\hline $80-90$ & 8 & $32 \%$ & 9 & $4 \%$ \\
\hline $90-100$ & 2 & $8 \%$ & & \\
\hline $100-110$ & & & & \\
\hline$>110$ & & & & \\
\hline
\end{tabular}

As shown above BP returned to normal range in both groups after delivery.

\section{DISCUSSION}

Effective methods for treatment of severe PIH are mandatory in modern obstetrics because pregnancy induced hypertension is the leading cause of maternal morbidity and one of the major contributing cause of perinatal mortity and morbidity, the later being mainly due to preterm delivery and fetal growth retardation. Pregnancy induced hypertension has been the focus of attention during last 20-25 years for obstetrician all over the world.

There is paucity of reference as far as use of labetalol is concerned. A prospective study was carried out in 50 randomly selected patients of severe hypertension in pregnancy. The patients were devided into two groups, One were with nifedipine and other with inj labetalol.

$80 \%$ patients in labetolol group were from age group 21-30 years while $84 \%$ patients in nifedipine group were from 21-30 years age group, so in both group of drugs most of patients belong to 2130 years of age. Hansel et al 1986 reported that risk of PIH increase with maternal age.

Highest incidence between 21-30 years age group that risk further increase in women over 35 years of age.

It was found that $68 \%$ patients in labetalol group and $84 \%$ patients in nifedipine group were 
primigravida. Higher incidence was found in primigravida in both the groups of drugs. Eastman, 19713 and Redman, 19845 states that it is the disease of primigravida. They believes that the disorder may in some way have an immunological basis that previous exposure to fetal antigen may be protective.

Long et al, 19876, Santema et al 19557, Kuo et al, 19558, Coonrod et al, 19559, reported that a pregnant women with twin gestation has three time the risk of developing PIH than does a women with singleton pregnancy. Higher incidence is related to a larger placenta in twin gestations which exposes the mother to a greater amount of paternal antigen.

Mac Gillivray 195810 found reduced incidence of $\mathrm{PIH}$ in women who completed second pregnancies as compared with primigravida. Mauricaeu 196411observed that primigravida especially older one are much more likely to develop pre eclampsia than multiparas. Hansen 198616 concluded that risk of PIH increased with maternal age. Women over 35 years of age have a two to four fold higher risk than younger women.

Eastman 1971 concluded that maternal death from hypertensive disorder in pregnancy chiefly PIH was inversely related to average income per capita. In this it seems that availability utilization and quality of antenatal care, was less accessible to low income group. It was also found in the present study.

$68 \%$ patients in nifedipine group and $64 \%$ patients in labetalol group were from gestational age between 30-36 weeks. Most of the patients in both groups of drugs presented in third trimester.

$72 \%$ patients in labetalol group shows improvement in blood pressure within $15 \mathrm{~min}$ of starting of therapy. Starting dose of Inj. Labetalol in severe PIH from $20 \mathrm{mg}$ IV and repeated at interval of $15 \mathrm{~min}$. Only $28 \%$ patients required an increase in the dose of drug for control of blood pressure, while in nifedipine group $60 \%$ patients required it or need to add the other antihypertensive .

Lamming et al 1979 concluded that significant fall in blood pressure only occurred in the group treated with inj labetalol and blood pressure control was better in this group. Symond et al 1980 reported that a more satisfactory control of blood pressure was obtained with inj labetalol with minimum side effects.

$64 \%$ patients in nifedipine \& $60 \%$ patients in labetalol group had induction of labour, however it is not significant.

Qurmalawi et al 1995 reported in their study that rate of induction of labour and rate of caesarean section was less in labetalol group. They concluded that labetalol may have some ripening effect on cervix and bishop score was also higher in this group.

$44 \%$ patients in nifedipine group were delivered by caesarean section, while in labetalol group $36 \%$ patients delivered by caesarean section. Operative delivery rate was more with nifedipine as compared to labetalol.

Comparable results were reported by Qurmalawi et al, 1995 and Symonds et al.

$48 \%$ babies in nifedipine group shifted to mother while this rate was $60 \%$ in labetalol group. Results are comparable to the study of Lamming et al, 1980, that labetalol had no apparent detrimental effects on foetus antenatally, during labour or postnataly.

Side effect observed including like headache, tachycardia and postural hypotension more in nifedipine group. While 2 cases $(8 \%)$ in labetalol group were having headache and other 2 cases $(8 \%)$ were having postural hypotension.

\section{SUMMARY AND CONCLUSION}

Cases in both the groups of were closely observed during labour and upto 48 hours after delivery. Foetal outcome was also noted in each cases.

In this study inj labetalol proven better for control of blood pressure as compared to nifedipine. $60 \%$ patients in nifedipine group required other antihypertensive or increase in the dose of drug while only $2 \%$ patients in labetalol needed to increase the dose of drug.

Rate of induction was almost equal in both group of drug 64\% patients in nifedipine and 60\% patients in labetalol group. Induction delivery 
interval was short in labetalol as compared to nifedipine.

14 cases of labetalol delivered within $12 \mathrm{hr}$ only 1 case delivered after $24 \mathrm{hr}$ of induction by hysterotomy. 9 cases of nifedipine delivered within $12 \mathrm{hr}$ and 7 cases delivered after $24 \mathrm{hr}$ of induction.

Those delivered after $24 \mathrm{hr}$ of induction had preterm or IUD baby and maintained their BP on antihypertensive (nifedipine or labetalol)

Caesarean section rate was more in nifedipine group $44 \%$ patients in nifedipine group were delivered by caesarean section while only $36 \%$ patients in labetalol were delivered by caesarean section. $64 \%$ patients in labetalol group and $56 \%$ patients in nifedipine group were delivered normally.

Incidence of side effect were more in nifedipine group. Postural hypotention, headache, tachycardia was reported only in nifedipine group. Incidence of postural hypotension $8 \%$ in labetalol group. In my study inj. labetalol was better than nifedipine because it shown less side effects, better perinatal outcome, better control of blood pressure and decreasing morbidity in severe hypertension in pregnancy.

It appears that inj Labetalol is more effective in lowering the diastolic BP in severe $\mathrm{PIH}$ as compared to Nifedipine. Further fewer patients needed other anti hypertensive drug in Labetalol group. Labetalol group had favorable parameters in all aspects. However larger studies are required to establish the superiority of inj Labetalol in PIH.

\section{REFERENCES}

1. Landheimer MD, Katz AI : Currenct concepts . Hypertension in pregnancy. N. Engl J Med 313: 675-680, 1985.

2. Pritchard JA, MacDonald PC, Gant N: Hypertensive disorder in pregnancy. In Williams Obstetrics Ed. 17, Norwalk, CT Appleton Century Crofts, p. 525.1985.

3. Eastman, NJ and Hellmann LN: Williams Obsterics, 12th ed., 1971.

4. Coonrod DV, Hickok DE, Zhu K. et al. Risk factors for preeclampsia in twin pregnancies: a population based cohort study Obstet Gynecol :85:645-50. 1995.

5. Redman CWJ, Bellin LJ and Sonnar J: Treatment of hypertension in pregnancy with methyldopa. Blood Pressure control\& side effects. Br. J. Gynaec 84:419, 1984.

6. Long PA, Oats JN, Preeclampsia in twin pregnancy- severity and pathogenesis. Aust. NZJ Obtet. Gynaecol 27:1-5, 1987.

7. Santema J G, Koppelaar I, Wallenburg HC. Hypertensive disorders in twin pregnancy. Eur J. Obstet Gynecol Report Biol: 58:9-13, 1995.

8. Kuo HH, Yang JM, Wang KG. Preeclampsia in multiple pregnancy. Chung Hua I Hsueh Tsa. Chih (Taipei) (Chin Med J) 55:392-5,1995.

9. Coonrod DV, Hickok DE, Zhu K. et al. Risk factors for preeclampsia in twin pregnancies: a population based cohort study Obstet Gynecol :85:645-50. 1995.

10. Macgillivray, et at Brit. J. Obstet Gynecol. 65:536, 1968.

11. Mauricaeu F: Quoted from Blood Presure proteinuria and oedema in pregnancy. New York p.28, 1964.

12. Hansen JP: Older maternal age and pregnancy outcome : A review of literature. Obstet Gynarcol Survey 41: 726, 1986.

13. Pepatsonis DM, Lok CA, Bos JM et. Al Calcium channel blocker in management of preterm labour and hypertension in pregnancy Eur. J. Obstet. Gynaecol. Report Biol. 2001, 97:122-140.

14. Grossman E, Messerli FH, Grodzicki T, Kowey P 1996 "Should a moratorium be placed on sublingual nifedipine capsule given for hypertensive emergencies" JAMA 276, (16) 1328-31.

15. Sibai BM,Barton JR,Expectent management of severe preeclampsia remote from term,patient selection, treatment, and delivery indication.Am J Obstet Gynecol 2007;196-514e-514e9. 